ELUA

ISSN 2171-6692

Núm. 35, 2021, págs. 333-336

https://doi.org/10.14198/ELUA2021.35.17

\title{
RUIZ GURILLO, L. (2019). HUMOR DE GÉNERO. DEL TEXTO A LA IDENTIDAD EN ESPAÑOL. MADRID/FRANKFURT AM MAIN: IBEROAMERICANA/VERVUERT, 186 PÁGINAS
}

\author{
Jose Antonio Ortega Gilabert \\ Universidad de Alicante. Grupo GRIALE, España \\ jaog7@alu.ua.es \\ https://orcid.org/0000-0001-9627-9410
}

El uso del humor en español desde un punto de vista principalmente lingüístico es una disciplina en la que Leonor Ruiz Gurillo aparece como uno de los máximos referentes. Más allá de considerarse así por figurar como directora del grupo GRIALE, el cual se encarga del estudio pragmático del humor y la ironía en la lengua española, podemos confiar tal hecho al gran número de publicaciones que ha proporcionado a la materia. Y es que, teniendo en cuenta que no resulta del todo fácil dar con estudios sobre el tema (especialmente en lo referente a estudios actuales), la cantera de autores que ha suministrado dicho grupo de investigación ha dado lugar a un alud de publicaciones que rellenan y actualizan el panorama enfocado en el español. Es en este punto donde encontramos la obra que tratamos, un trabajo que propone un análisis del humor de género, tomando "género" desde las dos perspectivas posibles: como género textual y como identidad de género. Así, se diferencian los resultados obtenidos en el estudio de los monólogos propuestos de los de las conversaciones coloquiales con carga humorística.

Entrando de lleno en la estructuración del libro, observamos que se divide en ocho capítulos principales, con sus apartados y subapartados, además de las referencias bibliográficas y anexos, también numerados. La organización de la obra en sí es bastante esquemática y clara, por lo que no resulta difícil seguir el hilo, como veremos a continuación.

Ya en la introducción se nos adelantan ciertos factores de peso en el trabajo, como el hecho de que se abordará el término género desde las perspectivas de identidad de género y género textual a lo largo de la obra. Además, se profundiza en varios aspectos que se desarrollarán más adelante o que cimientan las bases del estudio en sí, como el enfoque de la investigación de ambas concepciones del humor de género bajo las premisas del humor interaccional o la secuencia humorística, entre otras. Es así como se introduce al lector en el contexto de la situación actual del estudio del humor más relevante para este trabajo y se presenta el método de actuación, el cual se basará en el análisis de transcripciones de

Para citar esta reseña: Ortega Gilabert, Jose Antonio (2021). Ruiz Gurillo, L. (2019): Humor de género. Del texto a la identidad en español. Madrid/Frankfurt Am Main, Iberoamericana/Vervuert. ELUA, 35: 333-336. https://doi.org/10.14198/ELUA2021.35.17

(C) 2021 Jose Antonio Ortega Gilabert

Este trabajo está sujeto a una licencia de Reconocimiento 4.0 Internacional

de Creative Commons (CC BY 4.0) 
monólogos televisados y conversaciones espontáneas e improvisadas con carga humorística recogidas con anterioridad en un corpus lingüístico.

A partir de este punto todos los capítulos se muestran autoconclusivos (presentan sus propias conclusiones) y, a su vez, relacionados con los anteriores o siguientes. El segundo capítulo, "Géneros del humor", está segmentado en cuatro apartados con varios subapartados en dos de ellos. Aquí se nos presenta una división de los géneros textuales en relación con la aparición (o no) del humor, a pesar de que solo se incidirá en aquellos en los que el humor es obligatorio (monólogos) o es opcional, aunque esperado (conversación coloquial). Con ello, se pasa a una definición exhaustiva de ambos géneros donde, en lo respectivo a los monólogos, se repasa la historia de estos en el ámbito territorial español y se analizan los elementos retóricos más relevantes que usan los emisores (monologuistas) y lo que se espera de los receptores (audiencia), además de los elementos discursivos que definen al género. De igual forma, la conversación coloquial es estructurada, siguiendo los pasos del grupo Val.Es.Co. y Briz (coord. Grupo Val.Es.Co 1995; Briz 1996 y 1998; Briz y Grupo Val.Es.Co 2002), en rasgos primarios, los cuales definen a la conversación en sí, y rasgos coloquializadores.

Por su parte, el tercer capítulo, el cual está articulado en torno a cinco apartados, desarrolla una división, asentada en las premisas de Martin (2014), donde se nos presentan dos tipos de humor: el de actuación (planificado) y el conversacional (más improvisado). Visto esto, se examinan varias características de género (entendido como identidad) en el monólogo, tales como el número de monologuistas masculinos y femeninos en el stand-up a nivel mundial entre otras, repasando una serie de estudios que abordan el humor de actuación y, finalmente, en el ámbito español. De forma similar se procede con la conversación coloquial, profundizando en los estudios que abordan la diferencia del uso del discurso humorístico en hombres y mujeres, factor que más tarde será desarrollado y analizado en el capítulo siete.

Los siguientes capítulos están unidos entre sí, puesto que se dedican al análisis de los corpus humorísticos de los que se dispone para la realización del trabajo, en dependencia de ambas perspectivas de género que antes mencionábamos (como identidad y como género textual). Así, por orden, encontramos desde el capítulo cuatro al siete los análisis de "El monólogo como género humorístico", "El monólogo humorístico desde la perspectiva de género", "La conversación coloquial como género no humorístico" y "La conversación coloquial desde la perspectiva de género", siendo estos apartados los más extensos del trabajo.

En lo referente a la sección correspondiente al monólogo como género humorístico -con seis apartados principales y varios subapartados- se repasa y se analiza, sobre las transcripciones de monólogos de Eva Hache y Andreu Buenafuente, los recursos retóricos principales que componen este género textual. Es aquí donde se hace especial hincapié en el carácter oral e inmediato (o improvisado) de los monólogos, con sus marcadores y recursos de dicción, frente a la total planificación del guion escrito, donde se marcan los ganchos y remates del texto. Por tanto, se consideran varias características principales comunes en ambos humoristas, presentadas como planificación, inmediatez, cara a cara, retroalimentación y dinamismo. Ambos humoristas son objeto de estudio en sendos apartados dentro del capítulo, dividiendo estos en cinco subapartados respectivos referentes a las características que acabamos de mencionar.

Por otro lado, en la sección relacionada con la perspectiva de género en el monólogo humorístico, la cual se divide en cinco apartados principales, se analizan de forma cuantitativa los temas de las transcripciones recogidas de monólogos de Eva Hache, como humorista 
femenina de referencia. Con todo, se observa la predominancia de los discursos centrados en relaciones personales (casi la mitad de estos enfocados a temas sexuales), frente a un reducido número que se dirige más bien hacia temas laborales. La piedra angular de este capítulo es, especialmente, la presentación de porcentajes recogidos de los textos sobre relaciones personales, donde se analizan temas como el enfrentamiento de ambos sexos y en qué se diferencia la forma en la que se representa la imagen de la mujer y la del hombre en ellos. Cada uno de estos puntos está, de hecho, recogido en sus respectivos subapartados. Se destaca de todo lo anterior el hecho de la predominancia de textos donde la monologuista mantiene la jerarquía, refuerza la imagen femenina o los estereotipos. La autora, finalmente, concluye que Eva Hache no promueve un humor feminista subversivo, ya que encontramos un bajo porcentaje de discursos con este contenido.

Partiendo de las transcripciones de conversaciones coloquiales recogidas en el corpus de Val.Es.Co (Briz y grupo Val.Es.Co 2002; Cabedo y Pons en línea), en el capítulo seis, titulado "La conversación coloquial como género no humorístico", se analizan las que presentan carga humorística en relación al PIM (principio de interrupción mínima) (Eisterhold, Attardo y Boxer 2006), donde solo se interviene una vez de forma irónica, y su reacción. A pesar de dividirse en siete apartados principales, solo el sexto, referente al análisis cualitativo de estas conversaciones, se subdivide en seis partes más. Con todo, se observa una tendencia clara a continuar la conversación humorística con varias intervenciones en hablantes de lengua española. Al no ser necesariamente un chiste la conversación irónica, no siempre la respuesta viene acompañada de risas, ya que, como concluye la autora, esta puede ser mixta, o respondiendo a lo implicado o a lo dicho. Estas ideas principales se desarrollan en los subapartados del punto seis, mencionados anteriormente, los cuales corresponderían, por orden, a La ironía en una única intervención, Respuesta a lo dicho, Respuesta a lo implicado, Respuesta con risas, Respuesta mixta y Facilitando el modo humorístico.

Por último, en el capítulo siete se subrayan las características especiales y distintas del humor entre mujeres, el propio que ocurre entre hombres y el que se da en conversaciones mixtas. De igual forma, se parte de un análisis de conversaciones que demuestra que el PIM se da en mayor medida entre hombres o situaciones mixtas que entre mujeres, ya que el ambiente humorístico se fomenta más comúnmente entre mujeres. En conclusión, las conversaciones que son exclusivas de mujeres muestran un humor más cooperativo, con fines más solidarios y sociales, así como una tendencia hacia el autohumor. Por otro lado, los hombres utilizan el humor de forma más competitiva o como muestra de poder entre ellos y, contrariamente a lo que se pensaba con anterioridad, se encuentran algunos ejemplos donde también se recurre al autohumor. Finalmente, en lo que se refiere a las conversaciones mixtas, el humor se utiliza de forma solidaria, apaciguadora y cohesiva del grupo donde rara vez la mujer sigue el humor del hombre y viceversa.

Como colofón, el capítulo perteneciente a las conclusiones (capítulo ocho) se limita a sintetizar de forma bastante breve lo obtenido en los apartados conclusivos propios de cada capítulo, repasando la metodología utilizada y los puntos más importantes de la obra, que ya hemos ido mencionando más arriba. Más allá de indicar las referencias bibliográficas, marcadas como punto nueve, nos interesa abordar el capítulo diez, donde encontramos el anexo. Aquí se incluye el sistema de símbolos que aparece en las transcripciones de Val. Es.Co (Briz y grupo Val.Es.Co 2002: 28-38), lo cual hace mucho más comprensible la lectura de estas y ayuda a vislumbrar los rasgos kinésicos y orales que se pierden en el texto. 
Terminando con el análisis formal del libro se ha de subrayar la aparición de gráficas y figuras de diferentes formas y en color para ilustrar los porcentajes de los datos recibidos. Esto se da exclusivamente en los tres capítulos que más se requieren estas aplicaciones, es decir, el cinco ("El monólogo humorístico desde la perspectiva de género"), seis ("La conversación coloquial como género no humorístico") y siete ("La conversación coloquial desde la perspectiva de género"). Por supuesto, encontramos figuras o esquemas a lo largo de toda la obra utilizadas para aclarar las ideas principales, pero las únicas en color se reducen a las que recogen porcentajes y resultados del estudio principal.

En definitiva, estamos ante una obra original e innovadora para el estudio pragmático de la lengua española, pues aborda uno de los fenómenos menos presentes en la investigación lingüística hasta el momento. Asimismo, la perspectiva adoptada en relación con el humor verbal es singular, ya que se analiza la variable de género tanto en su dimensión identitaria como textual. Ello convierte este libro más bien en un punto de partida que de llegada, hecho que la propia autora subraya en más de una ocasión. Según ella, algunos aspectos apuntados en su trabajo deberían ser analizados en obras posteriores y da pie, de esta forma, a nuevas investigaciones que arrojen luz sobre las conclusiones que quedan pendientes en este libro. Por ello, podemos afirmar que Humor de género es un estudio fundamental para quien busque analizar el humor de forma pragmática, para quien esté interesado o interesada en las vertientes identitaria y textual del factor género que se manifiesta a través del humor y, en general, para toda aquella persona que desee indagar en el humor lingüístico y en los principales patrones que usamos los hablantes en su realización. Teniendo en cuenta el empleo de un lenguaje ameno y cercano, podemos admitir que se trata de una obra accesible hasta para lectores sin muchos conocimientos específicos sobre la materia, lo que refuerza aún más lo afirmado anteriormente. En conclusión, nos encontramos ante un trabajo conciso y no demasiado extenso que resulta claro y directo en sus planteamientos y desarrollo, lo cual suma valor a la hora de comprender las ideas expuestas, que pertenecen a un campo donde queda mucho por explorar y descubrir. Podemos, así, dar por hecho que este estudio servirá de referente para futuras obras que se adentren en la investigación sobre el humor de género.

\section{REFERENCIAS BIBLIOGRÁFICAS}

Briz, A. (1996). El español coloquial: situación y uso. Madrid: Arco/Libros.

Briz, A. (1998). El español coloquial en la conversación. Esbozo de Pragmagramática. Barcelona: Ariel.

Briz, A. (coord., Grupo Val.Es.Co) (1995). La conversación coloquial, Materiales para su estudio. Valencia: Universitat, Anejo XVI de Cuadernos de Filología.

Briz, A. y grupo Val.Es.Co (2002). Corpus de conversaciones coloquiales. Madrid: Arco/Libros.

Cabedo, A. y S. Pons (eds.) (2013). Corpus Val.Es.Co 2.0. Consultado online en www.valesco.es (10-01-2021).

Esiterhold, J., S. Attardo y D. Boxer (2006). "Reactions to irony in discourse: evidence for the least disruption principle". Journal of Pragmatics, 38, pp. 1239-1256.

Martin, R. A. (2014). "Humor and Gender: An Overview of Psychological Research". En Chiaro, D. y R. Baccolini (eds.). Gender and Humor. Interdisciplinary and International Perspectives. London: Routledge, pp. 123-146. 